\title{
Microstructural \& Optical Properties of Thin Layers in the Fabrication of Field Effect Transistors
}

\author{
Silpa S. Prasad ${ }^{1, *}$, Divya K. Nair ${ }^{2}$, K. Shreekrishna Kumar ${ }^{3}$ \\ ${ }^{1,2,3}$ School of Technology \& Applied Sciences, Mahatma Gandhi University, Pullarikunnu Campus, Kottayam, Kerala, India \\ ${ }^{*}$ College of Engineering, Kidangoor, Kottayam, Kerala, India
}

\begin{abstract}
A model is proposed which can attract considerable attention from the electronic circuits communities by exploring the effects of different dielectric thickness on the operation and scalability of field -effect transistors based on $\mathrm{V}_{2} \mathrm{O}_{5}$. Here the driving mechanism of carrier-generated field-effect transistors (FETs) with vanadium pentoxide $\left(V_{2} O_{5}\right)$ layers is discussed. For this scenario,

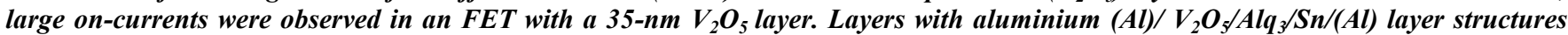
were also prepared. These devices exhibited a large current density in spite of their high carrier injection barriers between each layer and the Al electrodes. These FETs significantly employ achievable performance and improved field -effect mobilities. The structural changes of vanadium thin films are of vital importance for their practical applications. The aim of this paper is to determine the structural and optical properties of vanadium oxide thin films deposited by thermal evaporation. This work provides fundamental insight into the demonstration of charge transport characteristics in high-performance FETs by integrating the parameters with the Transistor Model.
\end{abstract}

Keywords: Field Effect transistor, thermal evaporation, vanadium pentoxide, thin films, structural properties

\section{Introduction}

During these last decades organic and inorganic semiconductor based electronics have attracted a huge attention. These materials are suitable for the fabrication of electronic circuits with multiple functionalities, low cost and on flexible substrates [3]. Applications range from sensors, RFID tags, e-skin and so on. Also several sensors can be made using Semiconductor, like temperature sensor, humidity sensor, light sensor etc. The properties like structural flexibility, low processing temperature and especially low costs make the semiconductor based devices suitable for these applications. The surface strain induced on semiconducting layer leads to the mechanical deformation and it results in variation of structural or morphological properties. This character is exploited for parameter sensing application and when it is undeserved there are techniques for reducing the mechanical deformation.

\section{Thin Film Transistors}

A thin film transistor (TFT) [3] is similar to a field effect transistor. An inorganic FET, consist of lightly-doped Si as active layer, where the applied voltage causes accumulation of minority charge carrier at the dielectric interface, e.g. holes in $n$ type material, which is termed an ,inversion layere Carrier injection in this channel from source to drain electrodes occurs by the application of bias voltages, resulting in a current flow. The basic model of a Field Effect Transistor (FET) is depicted in the figure.1.

Various techniques have been used for preparing thin films such as:

- Sol-gel,

- Electrochemical,

- Vacuum deposition techniques including plasma-

- Enhanced chemical vapor deposition (PECVD),
- Pulsed laser deposition,

- Thermal evaporation technique,

- Atomic layer deposition,

- Reactive magnetron sputtering,

- RF sputtering deposition.

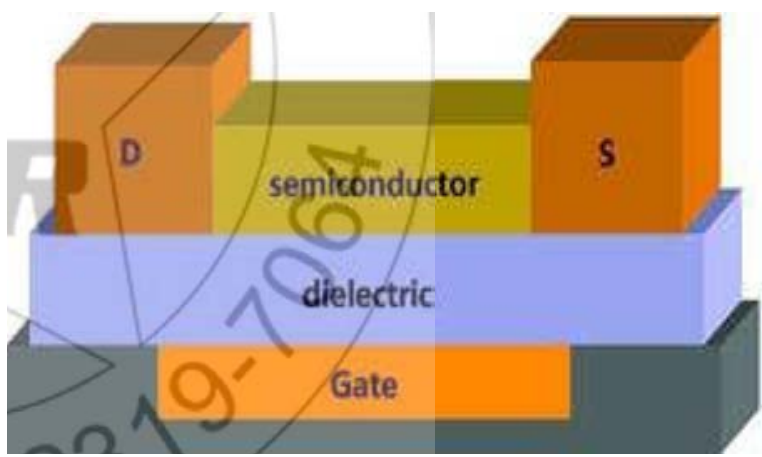

Figure 1: Basic model of an FET

Out of all these techniques, we have chosen the thermal evaporation technique for the deposition and fabrication of thin film transistor.

\section{Materials \& Methods}

The range of electronic properties of the transition metal oxides offers a unique opportunity to control the work function, and hence, the charge-injection properties. Therefore, modification of the organic/electrode interface by inserting Vanadium pentoxide $\left(\mathrm{V}_{2} \mathrm{O}_{5}\right)$ has received considerable attention in regards to organic electroluminescent devices. Similarly, the source-drain contacts in the inorganic TFTs have huge influence on device operation, through their contribution to the contact resistance arising from mismatch of the work functions, and/or interaction between the metal electrodes and the 


\section{International Journal of Science and Research (IJSR) \\ ISSN (Online): 2319-7064 \\ Index Copernicus Value (2015): 78.96 Impact Factor (2015): 6.391}

semiconductor. Adding $\mathrm{V}_{2} \mathrm{O}_{5}$, between the $S$ - $D$ contacts can greatly reduce the contact resistance for the TFTs.

Aluminium, $\mathrm{Al}$ is a very known contact material in electronics and exhibits a good corrosion resistance. The devices were made using Vanadium Pentoxide on Tin with a thickness of $35 \mathrm{~nm}, \mathrm{~V}_{2} \mathrm{O}_{5}$ functioned as the channel layer and Tin as the gate electrode and Alq3 as the gate insulator, respectively.

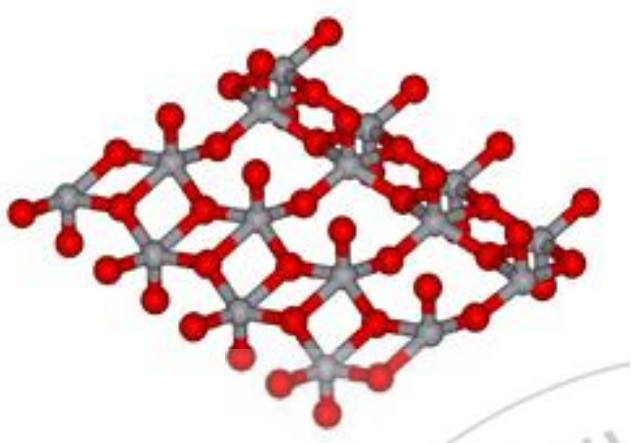

Figure 2: Structure of $\mathrm{V}_{2} \mathrm{O}_{5}$

Table 1: Three devices with different film thickness

\begin{tabular}{|c|c|c|c|c|c|}
\hline No. & $\begin{array}{c}\text { Thicknes } \\
\text { s of } \\
\text { Tin(nm) }\end{array}$ & $\begin{array}{c}\text { Thickness of } \\
\mathrm{V}_{2} \mathrm{O}_{5}(\mathrm{~nm})\end{array}$ & $\begin{array}{c}\text { Total } \\
\text { thickness } \\
(\mathrm{nm})\end{array}$ & $\begin{array}{c}\text { Threshold } \\
\text { Voltage }(\mathrm{V})\end{array}$ & $\begin{array}{c}\text { Mobility } \\
(\mathrm{cm} 2 /(\mathrm{Vs})\end{array}$ \\
\hline 1 & 68 & 10 & 78 & -5.8 & .33 \\
\hline 2 & 35 & 35 & 70 & -3.5 & .35 \\
\hline 3 & 10 & 50 & 60 & 0 & 0 \\
\hline
\end{tabular}

Vanadium Pentoxide, vanadic oxide, or vanadic anhydride, $\mathrm{V}_{2} \mathrm{O}_{5}[7]$, is one of the commonest of the compounds of vanadium[1][4]. Prior to the active layer deposition, the glass surface was cleaned by $\mathrm{UV} / \mathrm{O}_{3}$ cleaner. Then Tin was coated using thermal evaporation technique with a thickness of $35 \mathrm{~nm}$ and then following the gate insulator treatment, a $35-\mathrm{nm}$-thick layer of $\mathrm{V}_{2} \mathrm{O}_{5}$ is also coated using thermal evaporation method. $\mathrm{V}_{2} \mathrm{O}_{5}$ was obtained from Sigma-Aldrich, $98 \%$ purity was thermally evaporated at the rate of $0.5 \AA / \mathrm{s}$ from a molybdenum boat. Finally the $\mathrm{Al}$ electrodes were thermally evaporated onto the thin film through a shadow mask to form the $S-D$ electrodes. The thicknesses of $\mathrm{Al}$ films were $50 \mathrm{~nm}$. In addition, $\mathrm{Au}$ and $\mathrm{Al}$ were investigated as alternatives to the $S-D$ contacts. All the materials were used without any further purification. All thermal evaporations were done under a pressure of less than $6 \times 10^{-6}$ Torr while monitoring the film thickness with a quartz oscillator.

Three devices have been fabricated with three different thicknesses [5] for channel, dielectric and gate layers. Table. 1. Lists the characteristics of devices for different active layer thicknesses. Device 1 has an aluminium (Al) gate electrode/10-nm-thick $\mathrm{V}_{2} \mathrm{O}_{5}$ /Tin( $\mathrm{Sn}$ )/Aluminium(Al) FET structure with source (S) and drain (D) electrodes. The channel width and length of device A were set as $0.15 \mathrm{~cm}$ and $1.5 \times 10^{-3} \mathrm{~cm}$, respectively. Vanadium pentoxide films have been prepared using various physical and chemical techniques, such as thermal evaporation, electron beam evaporation, sol-gel, electrochemical deposition and pulsed laser ablation. Some unique features of $\mathrm{V}_{2} \mathrm{O}_{5}$ include its orthorhombic layered structure, high electrochromic activity, high stability and ease of thin film formation by numerous deposition techniques. Among the various preparation methods, the thermal evaporation method was one of the simplest methods, due to its deposition rate, good uniformity on the substrates and thickness control of the film. In this present work, the films were prepared by this technique and were characterized to study the optical and structural properties using XRD, SEM with EDAX, UV-Vis Spectroscopy and FT-IR Spectra.

Devices with $\mathrm{V}_{2} \mathrm{O}_{5}$ layers (x-nm thick) of different thicknesses were fabricated in order to investigate the optimal thickness required for an improved device performance. The combined thickness of the dielectric and $\mathrm{V}_{2} \mathrm{O}_{5}$ layers was fixed at $35 \mathrm{~nm}$, and the thickness of the $\mathrm{V}_{2} \mathrm{O}_{5}$ layer was varied from 10 to $60 \mathrm{~nm}$. Furthermore, to investigate the carrier generation at the interface between the dielectric and the $\mathrm{V}_{2} \mathrm{O}_{5}$ layers, fabrication of thin films as in the devices, device 1,2 and 3 as in table.1. were made. The area of device 2 was set as $2.0 \times 10-3 \mathrm{~cm}^{2}$, and the upper $\mathrm{Al}$ electrode was considered a positive electrode. High injection barriers at the interface between the $\mathrm{Al}$ electrode and the $\mathrm{V}_{2} \mathrm{O}_{5}$ layers or between the $\mathrm{Al}$ electrode and the dielectric layers might cause a few carriers to be injected. The as deposited $\mathrm{V}_{2} \mathrm{O}_{5}$ thin films are grey in colour. There is no evidence for any diffraction peak and so these films are amorphous in nature.

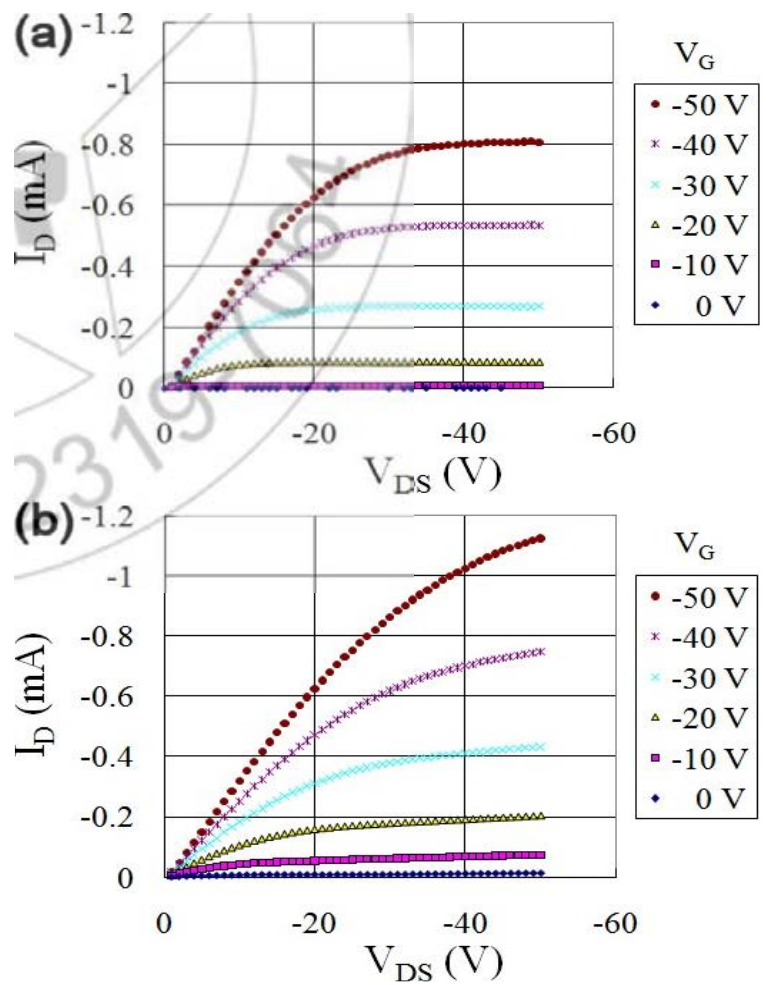

Figure 3: $I_{D}$ Versus $V_{D S}$ plot

Figure.3. shows a plot of the drain current $\left(\mathrm{I}_{\mathrm{D}}\right)$ vs. drainsource voltage $\left(\mathrm{V}_{\mathrm{DS}}\right)$ for devices 1 and 2 operating at various negative gate voltages $\left(\mathrm{V}_{\mathrm{G}}\right)[6]$. When a negative $\mathrm{V}_{\mathrm{G}}$ was applied, typical $I_{D}-V_{D S}$ curves were observed for devices 1 and 2. The value of $I_{D}$ increased linearly with $V_{D S}$ before 


\section{International Journal of Science and Research (IJSR) \\ ISSN (Online): 2319-7064}

Index Copernicus Value (2015): 78.96 | Impact Factor (2015): 6.391

gradually levelling off to reach current saturation. Current saturation was observed in devices 1 and 2 .

\section{i. Methods for Extraction of Mobility}

The prevalent method to extract the field-effect mobility is by using the expressions that describe the drain current $\left(I_{D}\right)$ for crystalline MOSFETs [1]. From simple FET theory, in the linear regime the device behaves like a resistor, which is described by the following equation,

$$
I_{D}=\frac{W \mu C_{i}}{L}\left[\left(V_{G}-V_{T}\right) V_{D}-V_{D}^{2} / 2\right]
$$

voltage, $V \mathrm{G}$ is gate-source voltage, $W$ is the transistor channel width, $L$ is the transistor channel length, $\mu$ is the field-effect mobility, $V_{T}$ is the threshold voltage, $\mathrm{V}_{\mathrm{D} \text {,sat }}$ is saturation voltage and $C_{i}$ is the capacitance of the gate oxide layer. $A s$ in the case of conventional metal-oxide semiconductor field-effect transistors (MOSFETs), it is well known that the field-effect mobility of an FET can be estimated using

$$
\mu_{\text {sat }}=\frac{2 L}{W C_{i}}\left(\frac{\partial \sqrt{I_{D}}}{\partial V_{G}}\right)^{2}
$$

The electron mobility characterizes how quickly an electron can move through a metal or semiconductor, when pulled by an electric field. In semiconductors, there is an analogous quantity for holes, called hole mobility. The term carrier mobility refers in general to both electron and hole mobility in semiconductors. The threshold voltage was determined from the intercept of the fitting line used to extract the mobility in the linear regime $\left(I_{D}-V_{G}\right)$ characteristics or the intercept of the fitting line used to extract the mobility in the saturation regime characteristics.[1]

\section{ii. XRD Analysis}

Figure.4. shows the diffraction pattern of $\mathrm{V}_{2} \mathrm{O}_{5}$ thin film which was deposited as the channel layer. Through analysis, it was found that the $\mathrm{V}_{2} \mathrm{O}_{5}$ films exhibited uniform thickness $[7,8]$. The XRD analysis proves that the $\mathrm{V}_{2} \mathrm{O}_{5}$ films is arranged in polycrystalline nature and the diffraction peaks for (2 200$),\left(\begin{array}{lll}3 & 2 & 0\end{array}\right)$ and (3 011$)$ planes were very prominent. The diffraction peaks at positions $2 \theta=22.4 \circ, 27.14 \circ$ and $52.22 \circ$ correspond to the (2 200$),\left(\begin{array}{lll}3 & 2 & 0\end{array}\right)$ and $\left(\begin{array}{lll}3 & 0 & 1\end{array}\right)$ planes respectively. The thin film layer is polycrystalline with varying degree of orientation and has FCC. The smoothness of the XRD pattern [4] confirms the uniformity in the grown film.

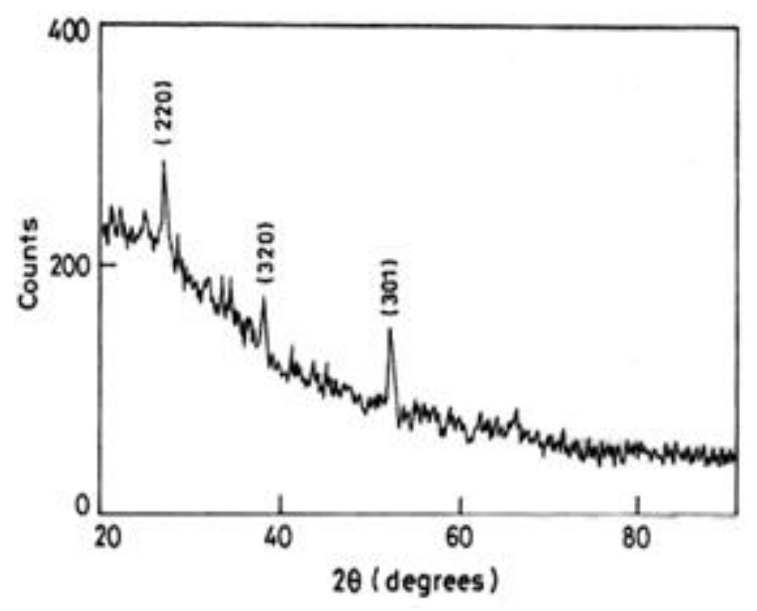

Figure 4: XRD Pattern of $\mathrm{V}_{2} \mathrm{O}_{5}$

\section{iii. Compositional Analysis}

The microstructure and morphology analysis of the as deposited $\mathrm{V}_{2} \mathrm{O}_{5}$ thin film was carried out. The SEM image in Fig. 5. details the homogeneity of the layer without any pinholes or pores.
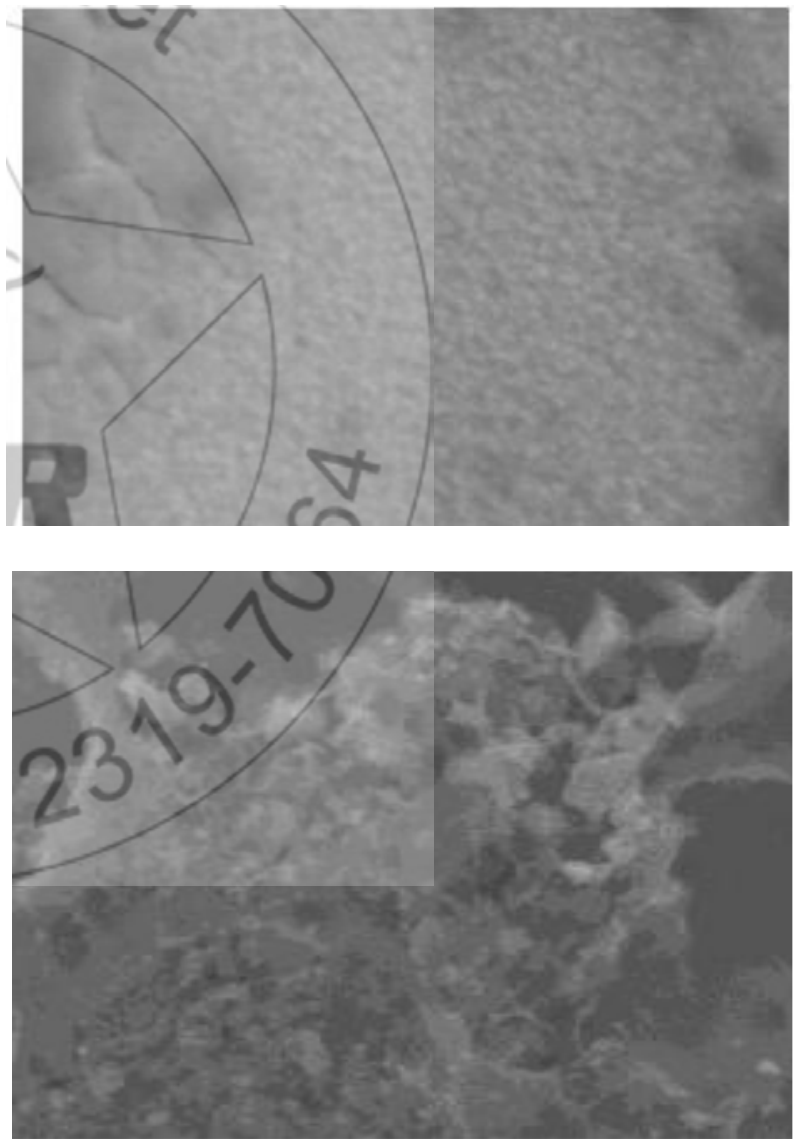

Figure 5: $\mathrm{SEM}$ images of $\mathrm{V}_{2} \mathrm{O}_{5}$ 


\section{International Journal of Science and Research (IJSR) \\ ISSN (Online): 2319-7064}

Index Copernicus Value (2015): 78.96 | Impact Factor (2015): 6.391

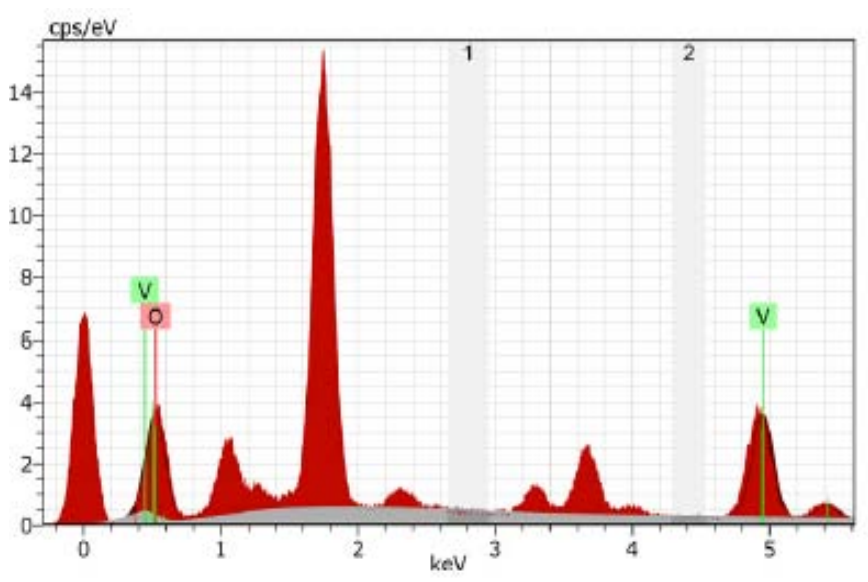

Figure 6: EDAX Spectra for $\mathrm{V}_{2} \mathrm{O}_{5}$

The shape of the particles is spherical in nature. The particle size observed from the SEM[4] images was in an order of $100-200 \mathrm{~nm}$. SEM images show the evolution of morphology with deposition temperature and the deposition time. The deposited $\mathrm{V}_{2} \mathrm{O}_{5}$ film has a very porous nature, and particle shape is three-dimensional and the elemental composition of the as deposited $\mathrm{V}_{2} \mathrm{O}_{5}$ film was also found. The presence of vanadium and oxygen were confirmed by EDAX analysis and their atomic weight percentages are calculated as $10.45 \%$ and $28.33 \%$ for vanadium and oxygen respectively. The EDAX analysis is shown in figure.6.

\section{iv. Optical studies}

The optical properties [1][4] of any material start from the electronic response to disturbance from the incident radiation and the transition between electronic states. Electronic properties and energy band structure of a solid are mainly based on its optical properties. Particularly, the frequency dependent complex refractive index and dielectric function are related to the electronic and band structure of the solid. Owing to the phase transition along with inherent drastic changes in the optical properties of the materials and inconsistent explanation of the phenomenon, the band gap calculation and absorption edge estimation have been studied. . Band gaps of $\mathrm{V}_{2} \mathrm{O}_{5}$, at room temperature, have been reported as $2.3 \mathrm{eV}$.

Optical transmittance and reflectance spectra over a wide wavelength range from 180to3200nm were measured with Lambda 19 Perkin-Elmer double beam spectrophotometer equipped with a $150 \mathrm{~mm}$ integrating sphere. The optical parameters are calculated from the transmittance spectrum in the $300 \mathrm{~nm}$ to $800 \mathrm{~nm}$ wavelength region. The as-deposited film has a steady transmittance of $75 \%$ in the visible region. The oscillations in the curves were due to interference effects that depend on the film thickness and the refractive index. The plot is linear, indicating a direct optical transition and the evaluated energy gap is $2.45 \mathrm{eV}$.

\section{Conclusion}

FETs with different thicknesses were fabricated and their electrical properties and drive principle discussed. Typical source-drain current $\left(\mathrm{I}_{\mathrm{D}}\right)$ vs. source-drain voltage $\left(\mathrm{V}_{\mathrm{DS}}\right)$ curves were observed under various negative gate voltages
$\left(\mathrm{V}_{\mathrm{G}}\right)$, and an improvement in the threshold voltage $\left(\mathrm{V}_{\mathrm{t}}\right)$ for the driving FET was observed in devices with 10- and 35nm-thick $\mathrm{V}_{2} \mathrm{O}_{5}$ layers . A larger current density was observed in devices fabricated by combining $\mathrm{V}_{2} \mathrm{O}_{5}$ layers. This indicated that carriers were generated at the interface between the dielectric and the $\mathrm{V}_{2} \mathrm{O}_{5}$ layers. We inferred that the charge transfer (CT) complexes that formed at the interface between the dielectric and the $\mathrm{V}_{2} \mathrm{O}_{5}$ layers were dissociated by the applied gate voltage and that the generated holes contributed to the drain current and the apparent $V_{t}$ improvement. The XRD pattern of the $\mathrm{V}_{2} \mathrm{O}_{5}$ film showed a polycrystalline nature with a preferential $\left(\begin{array}{lll}3 & 0 & 1\end{array}\right)$ orientation. Morphological studies showed a well-defined structure and elemental composition. The optical band gap of the $\mathrm{V}_{2} \mathrm{O}_{5}$ thin film was found to be $2.45 \mathrm{eV}$. The electro chromic studies and coloration efficiency of the vanadium pentoxide thin films are areas for future exploration.

\section{References}

[1] A.Mrigal, M. Addou, S. Khannyra, M. El Jouad, " $\mathrm{V}_{2} \mathrm{O}_{5}$ Thin Layers Elaborated By Spray Pyrolysis Deposition Time Effect on the Structural, Optical and Electrochemical Properties", International Journal of Advanced Research in Physical Science (IJARPS) Volume 2, Issue6, June 2015, PP 24-29

[2] Madhuri K.V.,Srinivasa rao K., et al. Optical and electrical properties of $\left(\mathrm{V}_{2} \mathrm{O}_{5}\right) 1 \square \mathrm{x}-(\mathrm{MoO} 3) \mathrm{x}$ thin films. J. Indian Inst. Sci., 2001, 81,P. 653-658.

[3] Ramana C.V., Naidu B.S., Hussain O.M., Pinto R. Low temperature growth of Vanadium pentoxide thin films produced by Pulsed Laser ablation. J. Phys. D: Appl. Phys., 2001, 34, L35-L38.K.

[4] Ramana C.V., Smith R.J., et al. Correlation betw- een Growth Conditions,Microstructure,and optical Properties in Pulsed Laser Deposited V2O5 Thin Films.

[5] Joseph, B.; Iadecola, A.; Maugeri, L.; Bendele, M.; Okubo, M.; Li, H.; Zhou, H.; Mizokawa, T.; Saini, N.L. Distinct Local Structure of Nanopar-ticles and Nanowires of V2O5 Probed by X-Ray Absorption Spectroscopy. Appl. Phys. Lett. 2013, 103.

[6] Chirayil, T.; Zavalij, P.Y.; Whittingham, M.S. Hydrothermal Synthesis of Vanadium Oxides. Chem.Mater. 1998, 10, 2629-2640.

\section{Author Profile}

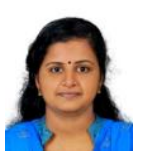

Silpa S. Prasad received her B.Tech degree in Electronics \& Communication engineering and M.Tech. degree in VLSI DESIGN from Amrita Viswavidyapeetham in 2008 and 2010, respectively. She is working as Assistant Professor in Department of Electronics \& Communication Engineering, Kidangoor, Kottayam, Kerala and also a Ph.D Research Scholar at Department of Electronics, in School of Technology \& Applied Sciences, Pullarikunnu Campus, Mahatma Gandhi University, Kottayam, Kerala, India . 